\title{
RANCANG BANGUN KONTROL KADAR AMONIA DAN PH AIR BERBASIS ARDUINO PADA BUDIDAYA IKAN
}

\author{
Dimasanggie Elul Talanta \\ Program Studi Teknik Mesin, Fakultas Teknik dan Informatika, Universitas PGRI Semarang \\ 1Dimasanggie98.daet@gmail.com
}

\begin{abstract}
Abstrak - Di dalam ekosistem kolam ikan terdapat berbagai macam faktor yang dapat menghambat pertumbuhan ikan atau bahkan dapat membunuh ikan, salah satunya adalah faktor air. Air sendiri terdapat berbagai macam faktor salah satunya kualitas kadar PH dan kadar amonia. Oleh karena itu tulisan ini membahas perancangan dan pembuatan alat kontrol kadar PH dan kadar amonia untuk memudahkan peternak dalam mengecek kadar PH dan kadar amonia di dalam kolam. Alat kontrol ini menggunakan sensor DFROBOT V.2 sebagai sensor PH dan sensor DS18B20 sebagai sensor suhu serta Arduino UNO kontrolernya.Metode yang digunakan untuk mengontrol amonia yaitu dengan perbandingan antara data dari PH dan suhu pada air kolam, alat ini akan bekerja apabila kadar amonia lebih dari 0, 8ppm dengan mengaktifkan aerator untuk menjaga amonia dalam air kolam tetap normal. Sedangkan untuk menjaga PH air lebih dari 6 dan kurang dari 7 maka dilakukan penambahan air kolam dengan mengaktifkan pompa air. Hasil dari penelitian ini dapat dijadikan sebagai acuan untuk penelitian kedepannya untuk pengembangan alat kontrol kadar PH dan amonia berbasis Arduino uno.
\end{abstract}

Kata Kunci-Budidaya ikan; kadar PH air; kadar amonia air;arduino UNO; kualitas air.

\begin{abstract}
In the fish pond ecosystem there are various factors that can inhibit fish growth or even kill fish, one of which is the water factor, the water itself has various factors, one of which is the quality of PH levels and amonia levels. Therefore, this paper discusses the design and manufacture of a control device for PH levels and amonia levels to make it easier for farmers to check PH levels and amonia levels in the pond. This control device uses a DFROBOT V.2 sensor as a PH sensor and a DS18B20 sensor as a temperature sensor as well as an Arduino UNO controller. The method used to control amonia is by comparing the data from PH and the temperature in the pool water, this tool will work if the amonia level is higher. from 0.8ppm by activating the aerator to keep the amonia in the pool water normal. Meanwhile, to maintain the PH of the water more than 6 and less than 7, it is necessary to add pond water by activating the water pump. The results of this study can be used as a reference for future research for the development of Arduino Uno-based PH and amonia level control devices.
\end{abstract}

Keywords - Fish farming; PH level of water; Amonia content of water; Arduino UNO; water quality.

\section{PENDAHULUAN}

Dalam proses budidaya ikan kualitas air sering diabaikan dalam pengelolaan kolam. Kualitas air yang buruk dapat menimbulkan masalah. Masalah utama berkaitan dengan kualitas air adalah meningkatnya kadar PH dan kadar amonia pada perairan tambak atau kolam buatan.

Meningkatnya kadar amonia dan kadar PH ini dapat menjadi racun tersendiri bagi ikan-ikan tersebut. Derajat keasaman suatu ekosistem ikan harus dalam keadaan netral dengan ketetapan pada angka 6-7, maka jika dalam keadaan kurang atau lebih dari itu akan mengganggu pertumbuhan karena dapat dikatakan air tersebut dalam keadaan tercemar, sedangkan pada amonia konsentrasi tinggi sangatlah bersifat toksik, dapat menyebabkan penurunan pasokan oksigen dalam jumlah besar dan dapat menyebabkan perubahan besar pada ekosistem perairan [14] kadar amonia akan menjadi salah satu ancaman yang sangat menakutkan jika dalam suatu ekosistem kolam tersebut melebihi $1,5 \mathrm{mg} / 1$, bahkan dalam kasus tertentu dalam kadar 0,025 mg/l ikan tidak dapat bertahan.

Ide pembuatan alat ini tercipta karena dorongan dari masalah di atas, alat ini menggunakan sensor $\mathrm{PH}$ DFROBOT V.2 untuk mendeteksi PH yang disalurkan oleh Arduino UNO ke pompa air untuk menambah dan menstabilkan kualitas air dari luar kolam, sedangkan untuk mendeteksi kadar amonia digunakan dua sensor yaitu sensor PH itu sendiri yang dikonfigurasikan dengan sensor suhu DS18B20 agar dapat mengetahui kadar amonia dan untuk menurunkan kadar amonia menggunakan alat aerator karena aerator dapat menambah oksigen yang dapat melancarkan proses nitrifikasi.

\section{PH air}

PH adalah suatu nilai yang menggambarkan tingkat keasaman atau alkalinitas dalam suatu larutan. Nilai PH antara angka 0 sampai 14 dengan ketentuan seperti pada tabel dibawah ini: 
Tabel 1 nilai PH [12]

\begin{tabular}{|c|c|}
\hline $\mathrm{pH}$ larutan & Sifat \\
\hline $\mathrm{pH}<7$ & Asam \\
\hline $\mathrm{pH}=7$ & Netral \\
\hline $\mathrm{Ph}>7$ & Basa \\
\hline
\end{tabular}

\section{Amonia air}

Amonia adalah produk pembuangan utama hasil dari pemecahan protein di dalam pakan ikan, lalu dibuang melewati insang ikan menjadi amonia yang tidak dapat terionisasi, jadi karna sifat utama dari amonia adalah toksik, oleh karena itu amonia sangatlah tidak baik jika melebihi batas konsentrasinya sebesar $1,5 \mathrm{mg} / \mathrm{l}$. Kadar amonia ini sangat beracun untuk ikan yang dibudidaya untuk kepentingan komersil dengan fokus kepadatan ion 1,5 mg/1 keatas, dan bahkan untuk sistuasi yang tidak terkendali fokus ion amonia yang dapat diterima oleh ikan budidaya hanya berkisar $0,25 \mathrm{mg} / 1$ [14].

\section{Sensor PH DFROBOT V.2}

Sensor PH adalah sebuah alat yang digunakan untuk mengetahui derajat keasaman dan basa dari sebuah larutan, PH meter itu sendiri memiliki range angka derajat keasaman dari 0-14 dengan tingkat netralnya ada di angka 6-7.

\section{Sensor Suhu DS18B20}

Sensor DS18B20 adalah sensor digital yang memiliki 12 bit $\mathrm{ADC}$ internal pada rentang suhu $-10^{\circ} \mathrm{C}$ sampai dengan suhu lebih dari $85^{\circ} \mathrm{C}$, sensor ini juga memiliki tingkat keakuratan kurang lebih 0,5 derajat. Sensor ini bekerja dengan protokol komunikasi 1-wire (one-wire).

\section{Arduino UNO}

Arduino Uno adalah suatu platform dalam satu paket berbentuk papan (board) yang didalamnya terdapat rangkaian elektronik (hardware) dan terdapat system pengembang (software) yang menggunakan sistem mikrokontroler jenis tertentu.

\section{Pompa air TAFFWARE}

Pompa air adalah alat yang digunakan untuk mengambil/menyalurkan air dari titik terendah ke titik tertinggi tergantung kekuatan dari pompa air tersebut, dan juga dapat menghantarkan air ke seluruh jaringan keran di rumah (jarak tergantung dari kekuatan pompa air). Sistem kerja pompa air ini sendiri dengan cara menghisap dan membuang air.

\section{Pompa udara aerator/aerasi}

Aerator adalah alat yang digunakan untuk menghasil gelembung-gelembung udara yang berfungsi untuk menambah pasokan oksigen ke dalam akuarium agar pasokan oksigen untuk ikan terpenuhi.

\section{Liquid Cristal Display (Led)}

Liquid Cristal Display adalah suatu alat yang dapat menampilakan suatu data menggunakan kristal cair untuk menampilan data tersebut, baik itu karakter, huruf ataupun grafik, alat ini memiliki bentuk tipis, dapat mengeluarkan sedikit panas, dan memiliki resolusi cukup tinggi.

\section{Relay dual chanel}

Relay adalah sebuah alat output yang berfungsi untuk switch on/off untuk perangkat lainnya. Relay ini dikontrol dari pin yang tertancap ke Arduino sehingga relay ini dapat melakukan pekerjaannya sesuai perintah dari Arduino.

\section{Power supply}

Power Supply digunakan untuk menyuplai tegangan ke seluruh perangkat yang dihubungkan, Power Supply juga selain memiliki peranan untuk menyuplai tegangan, juga memiliki peran untuk mengatur tinggi rendahnya voltase pada suatu komponen.

\section{Arduino IDE}

Arduino IDE (Integrated Development Environment) adalah software yang digunakan untuk memprogram kinerja board Arduino.

\section{METODE}

Penelitian dan pengembang (research and development) digunakan sebagai landasan pada penelitian ini yang bertujuan mengembangkan dari penelitian-penelitian yang sebelumnya. Metode ini juga terbagi lagi dan penelitian kali ini menggunakan jenis model waterfall karena model ini sendiri lebih sistematis dan berjalan sesuai landasan sekuensial dalam desain kali ini, berikut adalah tahapan dalam waterfall:

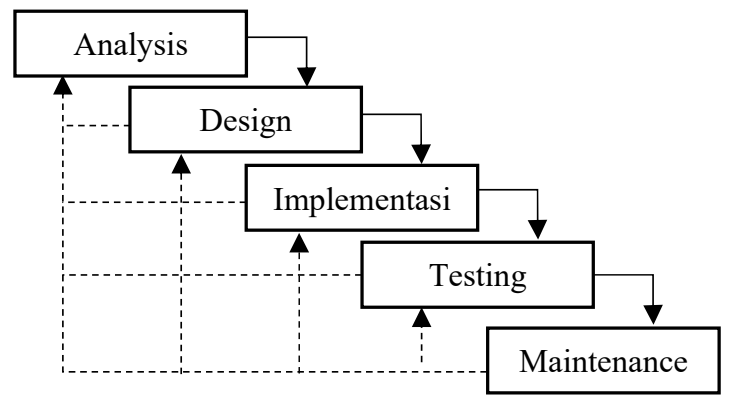

Gambar 1. Tahapan model penelitian dan jenis waterfall [25]

\section{A. Tahap analysis}

Dalam tahap penelitian ini mengembangkan dan menambah dari penelitian sebelumnya [7], [9], [11], dengan adanya sensor suhu yang berkolaborasi dengan sensor $\mathrm{PH}$ untuk mendapatkan nilai $\mathrm{PH}$, dan juga aerator sebagai penambah oksigen untuk melancarkan proses nitrifikasi agar amonia berkurang.

\section{B. Tahap design hardware}

Perangkat keras yang digunaka antara lain adalah sensor PH DFROBOT V.2, sensor suhu DS18B20, LCD, Arduino UNO, water pump, aerator, relay dualchanel, power supply, tombol on/off, step down, berikut adalah gambar rangkai keseluruhan: 


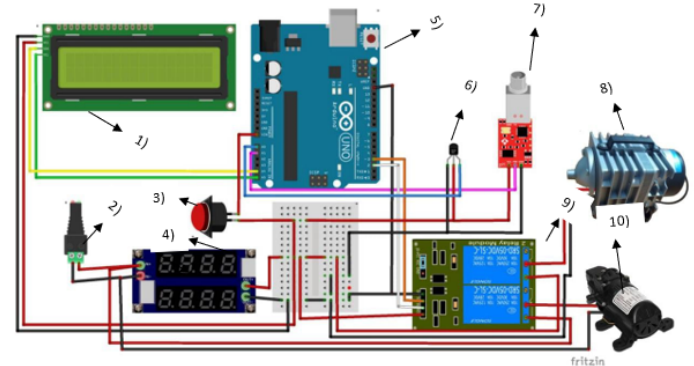

Gambar 2. desain elektronik alat

Berikut ini adalah deskripsi dari gambar hardware elektronik di atas:

1) LCD(Liquid Crystal Digital)bekerja untuk menampilkan data analog dari aktivitas mikrokontroler Arduino yang berkaitan dari sensor ph dan sensor amonia.

2) Power supply, digunakan untuk menyuplai teganggan ke seluruh komponen

3) Tombol on/off, berfungsi sebagai pemutus arus listrik dari power supply

4) Step down, bekerja untuk menurunkan tegangan yang disalurkan dari power supply

5) Mikrokontroler digunakan untuk menangkap sinyal dari sensor ph dan sensor amonia untuk selanjutnya diteruskan ke water pump dan aerator.

6) Sensor suhu digunakan untuk perpaduan dengan sensor ph untuk membaca kadar amonia pada air di kolam dan di salurkan kan ke Mikrokontroler agar di olah datanya.

7) Sensor ph bekerja untuk membaca kadar ph pada kolam ikan yang akan di teruskan pada Mikrokontroler.

8) Relay digunakan sebagai saklar listrik dan pada rancangan ini digunakan untuk penyambung dan pemutus water pump dan aerator.

9) Water pump sebagai feedback dari Sensor ph untuk menambah debit air dan menambah/mengurangi kadar ph agar stabil pada kolam ikan.

10)Aerator, sebagai feedback dari sensor Amonia untuk meningkatkan kadar oksigenn dan menghilangkan kadar gas amonia pada kolam ikan

\section{Rancangan System Kerja}

Alur sistem kerja alat ini adalah dengan melakukan pengukuran $\mathrm{PH}$, lalu disalurkan ke arduino untuk pengolahan data, setelah itu di lanjutkan ke relay yang bertugas sebagai sistem on/off pada pompa air, data olahan selain di salurkan ke relay juga disalurkan ke lcd untuk ditampilkan. Alur sistem ammonia sendiri hanya berbeda di sensornya yang menggunakan sistem penggabungan antara sensor $\mathrm{PH}$ dan sensor suhu untuk mengukur kadar amonia yang akan diteruskan untuk menyalakan aerator.

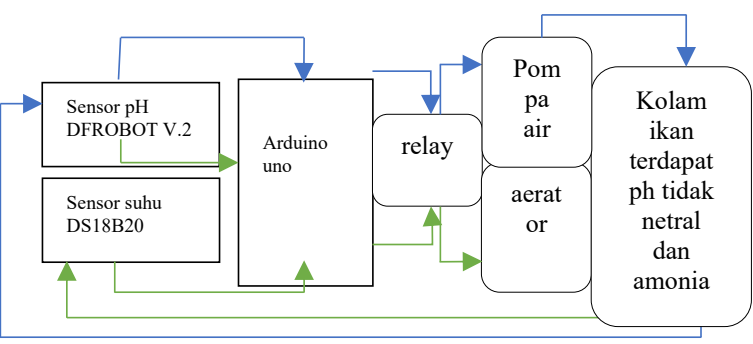

Gambar 3. Diagram Blok Sistem

\section{Desain kesuluruhan produk}

Berikut adalah gambar keseluruhan produk ketika sudah dirancang:

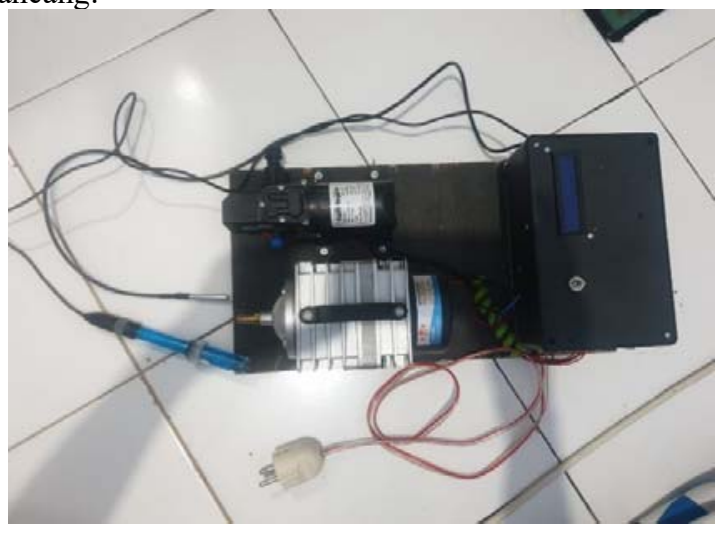

Gambar 4. Keseluruhan alat pengontrol kadar amonia dan PH

\section{HASIL DAN DISKUSI}

\section{A. Pengujian Alat}

Data yang ditampilkan dalam pengujian sistem antara lain adalah data dari uji sensor, dan uji kedua aquator, dan kedua sensor sudah diuji tingkat keakuratannya masingmasing, PH akan menyala jika pada lcd menunjukan angka kurang atau lebih dari 6-7, sedangkan amonia akan menyala pada 0,8 ppm dikarenakan mengacu pada tabel berikut:

Tabel 2. tabel amonia di air, penggabungan temperatur dan $\mathrm{PH}[21]$

\begin{tabular}{|c|c|c|c|c|c|c|c|c|c|}
\hline \multirow{2}{*}{$\begin{array}{l}\text { Temp } \\
\left({ }^{\circ} \mathrm{C}\right)\end{array}$} & \multicolumn{9}{|l|}{$\mathrm{pH}$} \\
\hline & 6 & 6,5 & 7 & 7,5 & 8 & 8,5 & 9 & 9,5 & 10 \\
\hline 0 & 0,00827 & 0,0261 & 0,0826 & 0,261 & 0,820 & 2,55 & 7,64 & 20,7 & 45,3 \\
\hline 1 & 0,00899 & 0,0284 & 0,0898 & 0,284 & 0,891 & 2,77 & 8,25 & 22,1 & 47,3 \\
\hline 2 & 0,0077 & 0,0309 & 0,0977 & 0,308 & 0,968 & 3,00 & 8,90 & 23,6 & 49,4 \\
\hline 3 & 0,0106 & 0,0336 & 0,106 & 0,335 & 1,05 & 3,25 & 9,60 & 25,1 & 51,5 \\
\hline 4 & 0,0115 & 0,0364 & 0,115 & 0,363 & 1,14 & 3,52 & 10,3 & 26,7 & 53,5 \\
\hline 5 & 0,0125 & 0,0395 & 0,125 & 0,394 & 1,23 & 3,80 & 11,1 & 28,3 & 55,6 \\
\hline 6 & 0,0136 & 0,0429 & 0,135 & 0,427 & 1,34 & 4,11 & 11,9 & 30,0 & 57,6 \\
\hline 7 & 0,0147 & 0,0464 & 0,147 & 0,462 & 1,45 & 4,44 & 12,8 & 317 & 59,5 \\
\hline 8 & 0,0159 & 0,0503 & 0,159 & 0,501 & 1,57 & 4,79 & 13,7 & 33,5 & 61,4 \\
\hline 9 & 0,0172 & 0,0544 & 0,172 & 0,542 & 1,69 & 5,16 & 14,7 & 35,3 & 63,3 \\
\hline 10 & 0,0186 & 0,0589 & 0,186 & 0,586 & 1,83 & 5,56 & 15,7 & 37,1 & 65,1 \\
\hline 11 & 0,0201 & 0,0637 & 0,201 & 0,663 & 1,97 & 5,99 & 16,8 & 38,9 & 66,8 \\
\hline 12 & 0,0218 & 0,0688 & 0,217 & 0,684 & 2,13 & 6,44 & 17,9 & 40,8 & 68,5 \\
\hline 13 & 0,0235 & 0,0743 & 0,235 & 0,738 & 2,30 & 6,92 & 19,0 & 42,6 & 70,2 \\
\hline 14 & 0,0254 & 0,0802 & 0,253 & 0,796 & 2,48 & 7,43 & 20,2 & 44,5 & 71,7 \\
\hline 15 & 0,0257 & 0,0865 & 0,273 & 0,859 & 2,67 & 7,97 & 21,5 & 46,4 & 73,3 \\
\hline 16 & 0,0295 & 0,0933 & 0,294 & 0,926 & 2,87 & 8,54 & 22,8 & 48,3 & 74,7 \\
\hline 17 & 0,0318 & 0,101 & 0,317 & 0,996 & 3,08 & 9,14 & 24,1 & 50,2 & 76,1 \\
\hline 18 & 0,0343 & 0,108 & 0,342 & 1,07 & 3,31 & 9,78 & 25,5 & 52,0 & 77,4 \\
\hline 19 & 0,0369 & 0,117 & 0,368 & 1,15 & 3,56 & 10,5 & 27,0 & 53,9 & 78,7 \\
\hline 20 & 0,0397 & 0,125 & 0,396 & 1,24 & 3,82 & 11,2 & 28,4 & 55,7 & 79,9 \\
\hline
\end{tabular}




\begin{tabular}{|l|l|l|l|l|l|l|l|l|l|}
\hline 21 & 0,0427 & 0,135 & 0,425 & 1,33 & 4,10 & 11,9 & 29,9 & 57,5 & 81,0 \\
\hline 22 & 0,0459 & 0,145 & 0,457 & 1,43 & 4,39 & 12,7 & 31,5 & 59,2 & 82,1 \\
\hline 23 & 0,0493 & 0,156 & 0,491 & 1,54 & 4,70 & 13,5 & 33,0 & 60,9 & 83,2 \\
\hline 24 & 0,0530 & 0,167 & 0,527 & 1,65 & 5,03 & 14,4 & 34,6 & 62,6 & 84,1 \\
\hline 25 & 0,0569 & 0,180 & 0,566 & 1,77 & 5,38 & 15,3 & 36,3 & 64,3 & 85,1 \\
\hline 26 & 0,0610 & 0,193 & 0,607 & 1,89 & 5,75 & 16,2 & 37,9 & 65,9 & 85,9 \\
\hline 27 & 0,0654 & 0,207 & 0,652 & 2,03 & 6,15 & 17,2 & 39,6 & 67,4 & 86,8 \\
\hline 28 &, 00701 & 0,221 & 0,697 & 2,17 & 6,56 & 18,2 & 41,2 & 68,9 & 87,5 \\
\hline 29 &, 00752 & 0,237 & 0,747 & 2,32 & 7,00 & 19,2 & 42,9 & 70,4 & 88,3 \\
\hline 30 &, 00805 & 0,254 & 0,799 & 2,48 & 7,46 & 20,3 & 44,6 & 71,8 & 89,0 \\
\hline
\end{tabular}

Dilihat dari data di atas angka yang bergambar merah adalah angka dari kerapatan amonia yang tidak baik bagi ikan, dan oleh karena acuan batasan beracun dari sebuah amonia itu $1,5 \mathrm{ppm}$ sedangkan pada konsentrasi tersebut $\mathrm{PH}$ akan melebihi 7,5 maka dari itu aerator akan menyala pada keadaan $0,8 \mathrm{ppm}$ dan waterpump akan menyala kurang dari 6 dan lebih dari 7.

1) Pengujian keakuratan sensor $\mathrm{PH}$

Pengujian keakuratan $\mathrm{PH}$ ini diuji secara 3x bertahap dan diuji antara sensor $\mathrm{PH}$ pada alat dengan sensor $\mathrm{PH}$ digital yang sebelumnya juga sudah dikalibrasi.

Tabel 3. hasil pengujian sensor PH dengan alat digital PH meter.

\begin{tabular}{|l|l|l|l|l|}
\hline No & $\begin{array}{l}\text { Output sensor pH } \\
\text { DFROBOT V.2 }\end{array}$ & $\begin{array}{l}\text { Output } \mathrm{pH} \\
\text { mater digital }\end{array}$ & Selisih & Eror \\
\hline 1 & 7,91 & 7,9 & 0,01 & $0,13 \%$ \\
\hline 2 & 8,02 & 8,0 & 0,02 & $0,25 \%$ \\
\hline 3 & 7,71 & 7,7 & 0,01 & $0,13 \%$ \\
\hline \multicolumn{2}{|l}{ Eror rata-rata } & 0,4 & $0,14 \%$ \\
\hline
\end{tabular}

2) Pengujian keakuratan sensor suhu

Pengujian suhu ini juga dilakukan $3 \mathrm{x}$ secara bertahap antara sensor suhu ds18b20 dengan thermometer, untuk mendapatkan keakuratan maksimal diperlukan kesabaran.

Tabel 4. hasil pengujian sensor suhu dengan thermometer

\begin{tabular}{|c|c|c|c|c|}
\hline No & $\begin{array}{l}\text { Output sensor } \\
\text { suhu DS1820 }\end{array}$ & $\begin{array}{l}\text { Output } \\
\text { thermometer }\end{array}$ & Selisih & Eror \\
\hline 1 & 28,06 & 28 & 0,06 & $0,2 \%$ \\
\hline 2 & 29,00 & 28 & 1 & $0,35 \%$ \\
\hline 3 & 28,06 & 28 & 0,06 & $0,2 \%$ \\
\hline \multicolumn{3}{|c|}{ Eror rata-rata } & 1,12 & $0,12 \%$ \\
\hline
\end{tabular}

\section{3) Pengujian keakuratan sensor amonia}

Sedangkan pengujian amonia ini sendiri berbeda dengan kedua pengujian di atas,karena pengujian ini hanya perlu melihat angka yang ditampilkan dalam LCD berapakah hasil amonia konfigurasi antara $\mathrm{PH}$ dan suhu dan diuji kekauratannya dengan tester amonia.

Tabel 5. hasil pengujian data amonia dengan tetra tes amonia

\begin{tabular}{|c|c|c|c|c|}
\hline No & $\begin{array}{l}\text { Output nilai } \\
\text { amonia pada alat }\end{array}$ & $\begin{array}{l}\text { Output tetra } \\
\text { tes amonia }\end{array}$ & Selisih & Eror \\
\hline 1 & 1,814 & 1,5 & 0,314 & $0,2 \%$ \\
\hline 2 & 1,866 & 1,5 & 0,366 & $0,24 \%$ \\
\hline 3 & 1,829 & 1,5 & 0,329 & $0,22 \%$ \\
\hline \multicolumn{3}{|c|}{ Eror rata-rata } & 1,009 & $1 \%$ \\
\hline
\end{tabular}

\section{B. Hasil Pengujian}

1) Hasil PH menyalakan pompa air

Pompa air akan menyala jikalau sensor ph menangkap jumlah ph pada air kurang dari 6 dan lebih dari 7 .
Pengujian ini menggunakan cara memanipulasi kondisi air dengan mengubah nilai $\mathrm{PH}$ dalam air menggunakan sebuah serbuk yang dimasukan ke dalam air untuk mengatur nilai $\mathrm{PH}$ pada air, dan hasilnya sebagai berikut:

Tabel 6.pada keadaan air asam (kurang dari 6)

\begin{tabular}{|l|c|c|}
\hline No & pH (Asam) & Water pump (on/off) \\
\hline 1 & 4,83 & On \\
\hline 2 & 5,09 & On \\
\hline 3 & 5,47 & On \\
\hline 4 & 5,72 & On \\
\hline 5 & 5,97 & On \\
\hline 6 & 6,26 & Off \\
\hline
\end{tabular}

Tabel 7.pada keadaan air basa (lebih dari 7)

\begin{tabular}{|l|c|c|}
\hline No & pH (Basa) & Water pump (on/off) \\
\hline 1 & 6,99 & Off \\
\hline 2 & 7,78 & Off \\
\hline 3 & 8,05 & On \\
\hline 4 & 8,59 & On \\
\hline 5 & 8,97 & On \\
\hline 6 & 9,32 & On \\
\hline
\end{tabular}

2) Hasil amonia menyalakan aerator

Aerator akan menyala jika nilainya melebihi $0,8 \mathrm{ppm}$, untuk mendapatkan nilai tersbut dilakukan pengambilan data dengan cara penggabungan antara sensor PH dengan sensor suhu dan didapatlah hasil seperti pada tabel berikut:

Tabel 8. Hasil amonia dengan PH tetap di kisaran 6,98 dan suhu berubah-ubah

\begin{tabular}{|c|c|c|c|}
\hline No & Suhu kolam & $\begin{array}{c}\text { Amonia (ppm } \\
\text { atau mg/l) }\end{array}$ & $\begin{array}{c}\text { Aerator } \\
\text { (on/off) }\end{array}$ \\
\hline 1 & 27,96 & 0,690 & Off \\
\hline 2 & 28,55 & 0,7 & Off \\
\hline 3 & 28,97 & 0,72 & Off \\
\hline 4 & 29,5 & 0,79 & Off \\
\hline 5 & 29,96 & 0,81 & On \\
\hline 6 & 30,08 & 0,85 & On \\
\hline
\end{tabular}

Tabel 9.Hasil sensor amonia dengan suhu tetap di kisaran $28,02^{\circ} \mathrm{C}$ dan ph berubah-ubah

\begin{tabular}{|c|c|c|c|}
\hline No & ph kolam & $\begin{array}{c}\text { Amonia (ppm } \\
\text { atau mg/l) }\end{array}$ & $\begin{array}{c}\text { Aerator } \\
\text { (on/off) }\end{array}$ \\
\hline 1 & 6,46 & 0,212 & Off \\
\hline 2 & 6,85 & 0,468 & Off \\
\hline 3 & 6,97 & 0,686 & Off \\
\hline 4 & 7,03 & 0,81 & On \\
\hline 5 & 7,2 & 1,45 & On \\
\hline 6 & 7,4 & 2,04 & On \\
\hline
\end{tabular}




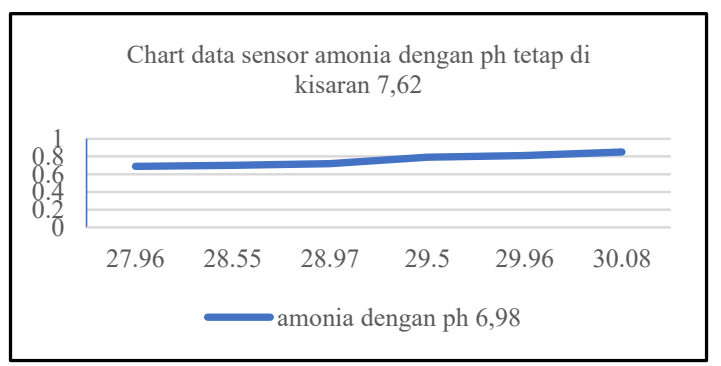

Gambar 5. Grafik pengujian dengan PH tetap 7,62

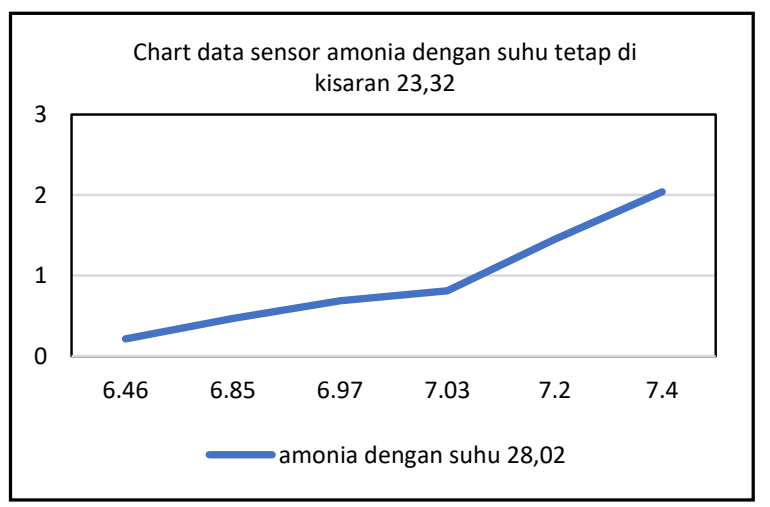

Gambar 6. Grafik pengujian dengan suhu tetap 23,32

\section{KESIMPULAN}

Berdasarkan penelitian yang telah dilakukan, kesimpulan yang dapat diambil sebagai berikut:

1. Penelitian ini menghasilkan sebuah alat yang dapat mengontrol $\mathrm{PH}$ dan amonia dengan basis Mikrokontroler Arduino UNO ini menggunkan sensor PH DFROBOT V.2 dengan feedback waterpump yang akan menyala pada kondisi asam dengan angka dibawah 6 dan basa dengan angka diatas 7 .

2. Kontrol amonia dengan konfigurasi dua sensor yaitu sensor PH bersama dengan sensor suhu DS18B20 yang dapat menciptakan suatu sistem aktuator berupa waterpump dan aerator untuk menjaga kestabilan kadar amonia pada level 0,8 ppm melalui konfigurasi perpaduan antara kedua sensor tersebut.

\section{Saran}

Berdasarkan penelitian yang telah dilakukan, maka didapati saran sebagai berikut:

1. Kadar salinitas sangat berpengaruh bagi kepadatan nilai amonia, maka dari itu disarankan untuk pengembangan selanjutnya dapat ditambah sensor salinitas.

2. Konsen dari sistem aerasi pada alat ini adalah dengan meningkatkan kadar oksigen agar amonia dapat terionisasi dengan baik, oleh sebab itu untuk penelitian selanjutnya dapat ditambahkan sensor DO agar dapat mengetahui seberapa akurasi kadar oksigen dalam ekosistem kolam.

3. Pompa air dan aerator yang digunakan pada penelitian ini spesifikasinya terlalu rendah dan tidak cocok dengan kolam yang berukuran besar, karena itulah disarankan untuk mengganti pompa air dan aerator yang spesifikasinya lebih tinggi jika ingin menggunakan di kolam yang lebih luas agar efisiensi waktu lebih meningkat.

4. Sistem pemantau alat ini masih meggunakan lcd yang artinya masih dapat dikembangkan, seperti dengan menambahkan sistem IOT untuk memudahkan dalam memantau kadar PH di dalam kolam tersebut.

\section{REFERENSI}

[1] Arduino Uno, Diakses pada 6 November 2020.

[2] Aerator YAMANO 004 ,(online), Diakses pada 9 Januari 2021.

[3] Adam J. Moleong, Steven. Metodologi Penelitian Kualitatif. Bandung:Remaja Rosdakarya, 1999.

[4] Sugiyono. (2016). Bandung: Alfabeta. Metode Dalam Penelitian (Skema Kuantitatif, Kualitatif dan Reseach and Development).

[5] Philip, B.(2005, agustus 25). "Air". Retrieved 1204,2019

[6] Rina Hayati,(14-07-19). Teknik Analisis Data, Macam Jenis Dan Cara Menulis.Diakses pada tanggal akses 18 November 2020

[7] Nugroho M.A., Rivai M..Sistem Monitoring untuk Mengontrol Kadar Amonia pada Ekosistem Kolam Ikan yang Diaplikasikan pada Raspberry Pi 3B.Surabaya:Fakultas Teknik,Institusi Teknologi Sepuluh Nopember, 2018

[8] Aditya Bagas. (2017). Prototipe Sistem Pengendealian PH Air Budidaya Ikan Pada Tambak Berbasis Arduino.

[9] Akbar M., \& Rivai M., (2019). Sistem Monitoring dan kontrol Kadar Amonia. December 2018. https://doi.org/10.12962/j23373539.v7i2.30920

[10] E. Barus, E., R. Pingak, K., \& A. Louk, C. (2018). OTOMALISASI SKEMA ALAT PENGONTROL PH DAN INFORMASI SUHU PADA AKUARIUM MENGGUNAKAN ARDUINO UNO DAN RASPBERRY PI model 3. Fisika Jurnal : Pengaplikasian Fisika sains, 3(2), 117-125.

[11] K.H.gilang ahmad dan B. Suprianto, (2019). Sistem Pengontrol PH,Kejernihan Air,dan Temperatur Air Budidaya Ikan Menggunakan Arduino Uno.

[12] Awaluddin K., Rukminasari N., \& Nadiarti (2014). Pengaruh PH air laut dengan konsentrasi kalsium dan laju pertumbuhan Halimeda.Jurnal Ilmu Kelautan Dan Perikanan, 24(1), 28-34.

[13] Muttaqin A., Sadewo A.D.B., \& Widasari E. R., (2017).Perancangan Kontrol Rumah menggunakan SmartPHone Berbasis Android dengan Koneksi Bluetooth Jurnal Teknologi Informasi Dan Ilmu Komputer, .1(5), .415-425.

[14] Wahyuningsih, S.,Gitarama, A. M.,(2020). Amonia Pada kolam Ikan. Syntax Literate; Jurnal Ilmiah Indonesia, 5(2), 112

[15] Widodo, S., Sutrisman, A., Putra, A. A., \& Amin M. M., (2017). Perancang Alat Monitoring Kadar Udara Bersih Dan Gas Berbahaya Co2, Ch4, Dan Co Di Ruangan menggunakan Mikrokontroler. Pseudocode, 4(2), 105-119.

[16] Bagas Aditya. (2017). Prototipe kontrol PH air kolam ikan pada tambak menggunakan arduino publikasi ilmiah.

[17] Rivai M., Akbar M., (2019). Sistem Kendali dan Pemantau Kadar Amonia. December 2018.

[18] Chen, S., Ling, J., \& Blancheton, J. P. (2006). Nitrification kinetics of biofilm as affected by water quality factors. Aquacultural Engineering, 34(3), 179-197.

[19] Ebeling, J. M., Timmons, M. B., \& Bisogni, J. J. (2006). and heterotroPHic removal of amonia-nitrogen in aquaculture systems Engineering analysis of the stoichiometry of PHotoautotroPHic , autotroPHic, and heterotroPHic removal of amonia - nitrogen in aquaculture systems. June.

[20] Er, K., Thunsronl, V., Russo, R. C., Luno, R. E., \& Tnunsron, N. R. V. (1975). Aqueous Amonia Equilibrium Calculations : Effect of $\mathrm{PH}$ and Temperature As indicated , V, 2379-2383.

[21] Francis-floyd, R., Watson, C., Petty, D., \& Pouder, D. B. (2015). Amonia in Aquatic Systems 1. 1-5.

[22] Hargreaves, J. A. (1998). Nitrogen biogeochemistry of aquaculture ponds. $181-212$

[23] Purnama, S. (2013). Produk Pembelajaran Bahasa Arab. Literasi, 4(1), 19-32. 
[24] Rahmaibu F. H. (2016). Pengembangan Media Pembelajaran Berbasis Multimedia Dengan Menggunakan Adobe Flash Untuk Meningkatkan Hasil Belajar Pkn.,Studi Kasus: Sdi Al Madina Semarang.

[25] Wiro Sasmito, G. (2017). Penerapan Metode Waterfall Pada Sistem Informasi Geografis Industri di Kabupaten Tegal. Jurnal Informatika:Jurnal Pengembangan IT (JPIT), 2(1), 6-12.
[26] YSI environmental. (2010). Understanding Amonia in Aquaculture Ponds. YSI Application Note, 3 . 